\title{
Pengaruh Solvabilitas terhadap Profitabilitas (Studi pada Perusahaan Asuransi Kerugian yang Terdaftar di Bursa Efek Indonesia Tahun 2013-2018)
}

Solvability's effect towards profitability (study at loss insurance companies listed Indonesia Stock Exchange 2013-2018)

\section{Muthia Nur Soniati}

Program Studi D3 Keuangan dan Perbankan, Politeknik Negeri Bandung E-mail: muthia.nur.kepn17@polban.ac.id

\section{Ruhadi}

Jurusan Akuntansi, Politeknik Negeri Bandung

E-mail: ruhadi@polban.ac.id

\section{Mochamad Edman Syarief}

Jurusan Akuntansi, Politeknik Negeri Bandung

E-mail: edman.syarief@polban.ac.id

\begin{abstract}
Insurance Company is developing, proved with the amount of insurance companies now, because companies need to minimalize their risk. There were several insurance companies warned by Financial Services Authority. This research has purpose to uncover the impact of Risk. Based Capital to Return On Asset.The independent variable is $\mathrm{RBC}$ and dependent variable is $\mathrm{ROA}$. The methode is explanatory and quantitative methode with secondary data which is annual financial reports period 2013 - 2018 in insurance companies listed on Indonesia Stock. Exchangd that dertermined 5 companies as sample. The statistic are classic assumption test, simple linear regretion, coefficient of determination, and hypothesis test with SPSS version 23. The result by $t$ test showed that Risk Based Capital has positive and significant influence on the Return On Asse. Where the change in Risk Based Capital can explain the change in Return On Asset by 44.9\% while the rest is influenced by other factors.
\end{abstract}

Keywords: insurance, risk based capital, return on asset

\section{Pendahuluan}

Manusia pasti memiliki kebutuhannya masing-masing, dan untuk memenuhi kebutuhannya manusia pasti menghadapi sesuatu yang tidak pasti entah baik maupun buruk (Ganie, 2013). Sesuatu yang tidak pasti ini selanjutnya disebut risiko, dapat terjadi kapanpun dan dapat menimbulkan hal yang tidak dapat diperkirakan. Untuk menghindari ancaman dari risiko yang lebih besar perlu adanya kesadaran masyarakat untuk melindungi dan memberi jaminan dirinya atas kehidupan, asetnya, kesehatan jiwa dan batinnya, hingga masa depan generasi penerusnya, sehingga saat besar risiko yang dihadapi diatas kemampuan mereka, ada yang menanggung kerugian tersebut. Ini lah yang menjadi latar belakang adanya perusahaan asuransi.

Menjadi nasabah asuransi penuh dengan risiko, maka pemerintah menetapkan syarat kesehatan perusahaan asuransi untuk melindungi nasabah asuransi, pemilik saham dan industri perasuransian nasional. Maka dari itu dikeluarkanlah KMK (No 481/KMK.017/1999) oleh 
pemerintah pada tahun 1999 yang selanjutnya direvisi menjadi (No 424/KMK.06/2003) yang berisi bahwa Risk Based Capital sebagai metode untuk mengetahui solvabilitas pada perusahaan asuransi reasuransi.

Angka RBC menunjukkan seberapa besar modal yang digunakan perusahaan untuk menyelesaikan liabilitasnya sebagai perusahaan sebagai perusahaan asuransi (Agustin, F., Suangga, A., \& Sugiharto, 2018). RBC ini sangat penting karena jika sampai tidak tercapai sesuai syarat kesehatan yang ditentukan, perusahaan terkait diharuskan memenuhi terlebih dahulu RBC nya baru dapat melakukan pembagian deviden dan tingkat RBC yang tinggi ini menjadi salah satu tolak ukur bahwa perusahaan asuransi terkait dalam keadaan sehat dan dapat menjamin risiko yang dihadapinya (Sastri et al., 2017).

Selain RBC atau rasio solvabilitas diatas, perusahaan asuransi pasti memiliki tujuan untuk mendapat keuntungan yang maksimal tiap tahunnya, yang selanjutnya di cerminkan dalam rasio profitabilitas, Salah satu rasionya ialah Return On Asset, rasio ini berfungsi untuk menunjukkan laba bersih (setelah dikurangi pajak) yang didapat dari pengelolaan aset yang dimiliki perusahaan terkait. ROA juga mencerminkan bagaimana perusahaan mengendalikan aset yang ada berproduktivitas dengan bagus atau tidak.

Berikut ini disajikan tabel data RBC dan ROA Perusahaan Asuransi Kerugian terdaftar di Bursa Efek Indonesia 2013-2018:

Gambar 1.1 Grafik Persentase RBC

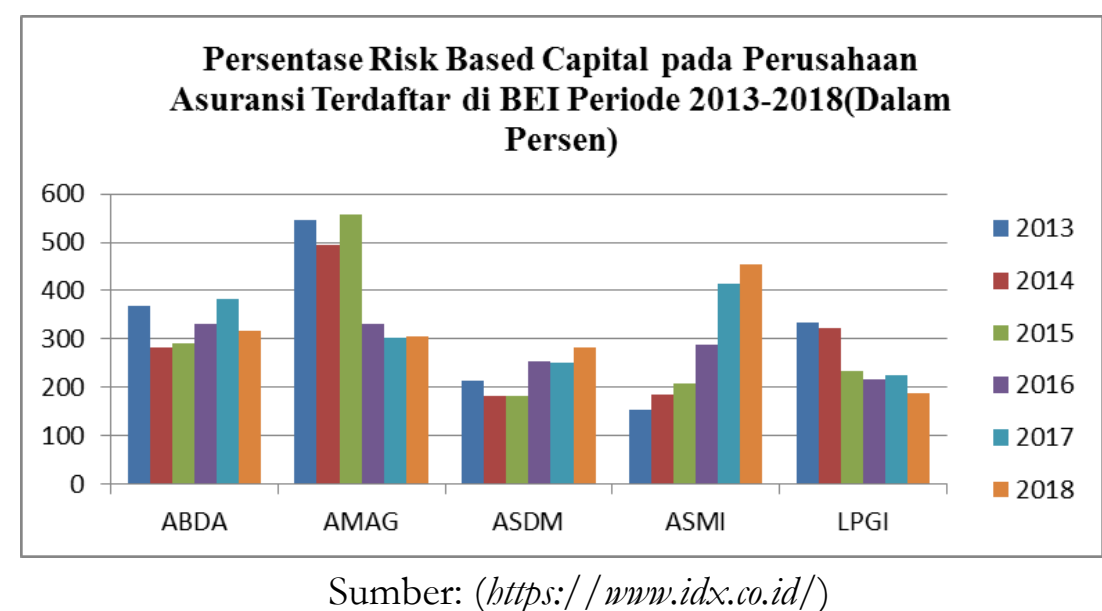

Gambar 1.2 Grafik Persentase ROA

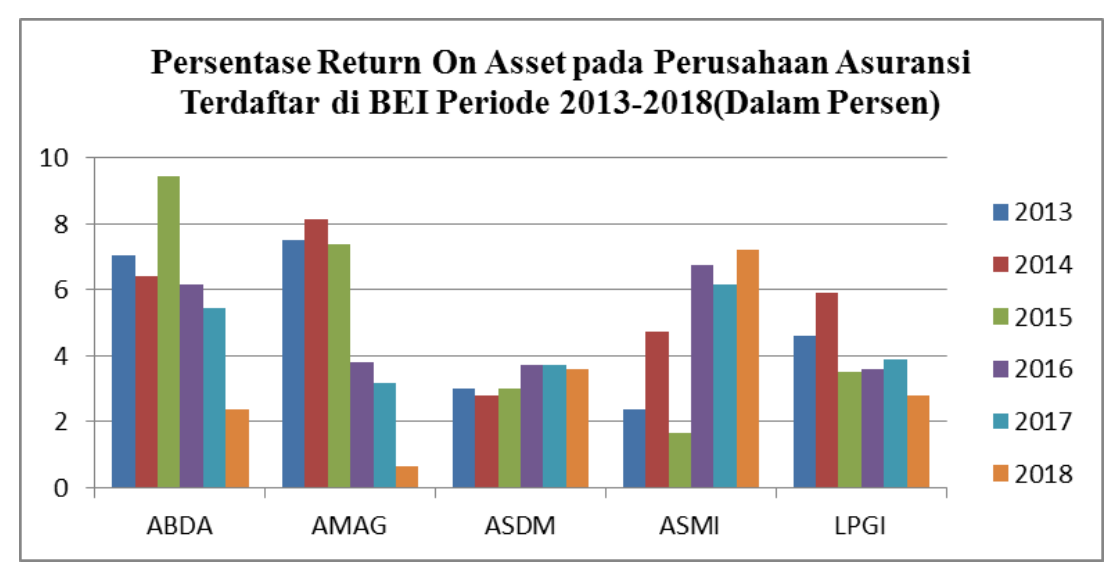

Sumber: (bttps://www.idx.co.id/) 
Dapat dilihat persentase RBC dan ROA pada masing-masing perusahaan yang fluktuatif. Pada perusahaan Asuransi Bina Dana Arta Tbk. (ABDA) 2014 ke 2015 pada RBC terjadi kenaikan begitupun dengan ROA terjadi kenaikan ini diduga merupakan indikasi adanya relasi positif RBC terhadap ROA. Sedangkan, pada perusahaan Asuransi Dayin Mitra Tbk (ASDM) tahun 2016 ke tahun 2017 RBC mengalami penurunan sedangkan ROA mengalami kenaikan ini diduga adanya indikasi relasi negatif dari RBC terhadap ROA.

Dari penelitian sebelumnya pun ada yang memiliki hasil yang berbeda - beda dikarenakan periode, perusahaan dan variabel pendukung yang berbeda, seperti berikut:

Penelitian yang dilakukan oleh (Pratama, 2013), FISIP UI, yang meneliti mengenai "Pengaruh Risk Based Capital, Penerimaan Premi, dan Beban Klaim terhadap Profitabilitas (ROA) pada Perusahaan Asuransi Kerugian" mendapat hasil berupa RBC berpengaruh parsial pada ROA. Sedangkan (Fitriani, 2014), UNISBA, yang meneliti mengenai "Pengaruh Risk Based Capital terhadap Profitabilitas Asuransi Syariah AXA Mandiri" mendapat hasil bahwa RBC tidak ada pengaruh terhadap ROA.

Berdasarkan jelasan diatas, Penulis memutuskan untuk mengajukan penelitian bwejudul "Pengaruh Solvabilitas Terhadap Profitabilitas (Studi Pada Perusahaan Asuransi Kerugian Terdaftar di Bursa Efek Indonesia Periode 2013 - 2018)".

\section{Kajian Pustakaa}

\subsection{Dasar Teori}

\subsubsection{Asuransi}

Ada 2 (dua) pihak terlibat didalamnya, ada tertanggung dan penanggung. Penanggung ini adalah orang yang menjamin dirinya akan mengganti dari satu maupun lebih kerugian yang dihadapi tertanggung, dan penanggung ini memberi bayaran kerugian terjadi karena risiko yang dihadapi tertanggung yang bayar premi ke penanggung untuk balas jasanya, berupa pembayaran yang relatif kecil dan dibayar secara periodik kepada penanggung untuk menukarkan risiko yang nantinya dibayarkan oleh penanggung. Asuransi bertujuan untuk memberi proteksi akan kerugian keuangan yang terjadi karena berbagai kejadian yang tidak dapat diduga sebelumnya (Budiarjo, 2015)

(Magee, 1955) dalam (Salim, 1995), menggolongkan Asuransi seperti berikut :

1. Jaminan Sosial (Social Insurance), berupa "asuransi yang wajib dimiliki”.

2. Asuransi Sukarela (Voluntary Insurance), mendaftar sukarela dan tidak dipaksa.

Asuransi sukarela ada 2 macam.

a. Asuransi Pemerintahan (Goverment Insurance), yaitu asuransi yang dijalankan oleh Negara

b. Asuransi Komersil (Commercial Insurance), asuransi yang tujuannya untuk melindungi dirinya, keluarga maupun perusahaannya dari risiko yang akan mereka hadapi dan untuk meraih keuntungan sebanyak-banyaknya. Commercial Insurance dapat dibagi menjadi:

a) Asuransi Jiwa (Personal Life Insurance), untuk menjamin kerugian yang terjadi karena sakit, kecelakaan dan kematian.

b) Asuransi Kerugian (Property Insurance) untuk menjamin kerugian yang terjadi akibat perampokan, kebakaran, dan lain-lain.

\subsubsection{Kinerja Keuangan}

Sebuah ketetapan yang berisi ukuran yang memperlihatkan keberhasilan suatu perusahaan menggapai keuntungan (Sucipto, 2003) dan menurut Ikatan Akuntansi Indonesia, 
2007, cerminan kecakapan perusahaan untuk mengendalikan segala sumber daya yang dikelola. Analisis yang umum digunakan adalah analisis rasio.

\subsubsection{Analisis Rasio Keuangan}

Sebuah cara agar diketahuinya letak pos tertentu di laporan, laba rugi maupun neraca yang nantinya dibandingkanlah angka yang tersedia dengan angka yang lain (Kasmir., 2014) .

Rasio dalam keuangan dapat digolongkan sebagai berikut (Hanafi, 2016):

1. Rasio Likuiditas, rasio yang mengukur kecakapan perusahaan untuk memenuhi kewajiban jangka pendeknya.

2. Rasio Aktivitas, rasio yang mengukur seberapa efektif penggunaan aset dari tingkat aktivitas yang terjadi.

3. Rasio Solvabilitas, rasio yang mengukur kecakapan perusahaan dalam memenuhi kewajiban jangka panjangnya.

4. Rasio Profitabilitas, rasio yang melihat kemampuan perusahaan menghasilkan keuntungan (Profit).

5. Rasio Pasar, rasio yang digunakan untuk melihat perkembangan nilai pasar sebuah perusahaan.

\subsubsection{Solvabilitas}

Solvabilitas bertujuan untuk mengetahui bagaimana aktiva dapat membantu biaya hutang maupun modal sendiri dan untuk mendapat informasi mengenai kecakapan perusahaan untuk bersedia memenuhi liabilitas jangka pendek dan panjangnya.

Dalam UU No. 21992 Tentang Usaha Perasuransian yang mengatur usaha asuransi, pasal 11 (1) mengatakan; usaha perasuransian akan diberi pengawasan dan binaan mengenai kesehatan keuangannya yang akan dilihat dari:

a. Batas Tingkat Solvabilitas Atau Risk Based Capital

b. Retention

c. Reinsurance.

d. Invest.

e. Technically Reserve

\subsubsection{Risk Based Capital}

Menurut (Ludovicus, 2006), Jika di industri perbankan ada rasio Capital Adequacy Ratio, di industri asuransi rasio tersebut dikenal dengan Risk Based Capital.

Telah dikatakan bahwa Risk Based Capital adalah rasio pemberi informasi mengenai tingkat keamanan yang mencerminkan kesehatan perusahaan asuransi yang seharusnya dimiliki sebuah perusahaan asuransi dengan tingkat paling kecil $120 \%$, dimana $20 \%$ itu adalah ketentuan bagi perusahaan untuk memiliki aset atau kekayaan minimal 20\%.

Ini cara perhitungan Risk Based Capital yang terdapat pada No 424/KMK.06/2003:

$$
\text { Risk Based Capital }=\frac{\text { Tingkat Solvabilitas }}{\text { Batas Tingkat Solvabilitas }}
$$

Jika ternyata Risk Based Capital ini memiliki angka kurang dari 120\% untuk meminimalkan risiko kerugian yang kemungkinan akan muncul karena pengendalian kekayaan dan kewajiban perusahaan asuransi, maka sesuai PMK No 424/KMK.06/2003 usaha asuransi tersebut wajib melakukan perencanaan dan aksi untuk menyehatkan kembali keuangannya dalam tenggat waktu yang ditentukan dan saat itu terjadi perusahaan asuransi dilarang untuk membagikan dividen maupun hadiah atau bayaran dengan bentuk apapun kepada pemilik saham. 


\subsubsection{Profitabilitas}

Profitabilitas merupakan kecakapan perusahaan untuk menerima keuntungan yang berhubungan dengan aset maupun modal (Winarni, 2005). Target terbesar rasio ini ialah keuntungan perusahaan. Untuk mengetahui berapa besar investasi yang perusahaan lakukan dapat memberi return yang setimpal dengan yang diharapkan membuat ROA ini menjadi rasio yang sangat penting.Pada penelitian kali ini, penulis memakai salah satu rasio profitabilitas yang bernama Return On Asset (ROA).

\subsubsection{Return On Asset}

Rasio yang bertujuan agar mengetahui laba yang sudah terkurangi pajak dari pengendalian aset, untuk mengukur keproduktivitasan aset, dan menjadi salah satu faktor penting untuk pemegang saham, semakin besar ROA makin besar deviden yang akan didapat. "Angka ROA dapat dikatakan baik jika > 2\%" (Lestari ;Sugiharto, 2007).

Berikut perhitungannya:

$$
\text { Return On Asset }=\frac{\text { Laba Setelah Pajak }(E A T)}{\text { Total Asset }} \times 100 \%
$$

\subsection{Hipotesis Penelitian}

Tabel 2.2 Tabel Penelitian Sejenis Sebelumnya

\begin{tabular}{|c|c|c|c|c|c|}
\hline No. & Tahun & Peneliti & $\begin{array}{c}\text { Judul } \\
\text { Penelitian }\end{array}$ & $\begin{array}{l}\text { Variabel } \\
\text { Penelitian }\end{array}$ & $\begin{array}{c}\text { Hasill } \\
\text { Penelitian }\end{array}$ \\
\hline 1 & 2013 & Pratama, & $\begin{array}{c}\text { Pengaruh Risk } \\
\text { Based Capital, } \\
\text { Penerimaan } \\
\text { Premi, Beban } \\
\text { Klaim } \\
\text { terhadap } \\
\text { Profitabilitas } \\
\text { Perusahaan } \\
\text { Asuransi } \\
\text { Kerugian }\end{array}$ & $\begin{array}{c}\text { Independen : } \\
\text { RBC, } \\
\text { Penerimaan } \\
\text { Premi, Beban } \\
\text { Klaim } \\
\text { Dependen : } \\
\text { ROA }\end{array}$ & $\begin{array}{l}\text { Beban klaim, } \\
\text { pelrolehan premi } \\
\text { dan RBC } \\
\text { pengaruhnya } \\
\text { signifikan\&positi } \\
\text { f thd ROA }\end{array}$ \\
\hline 2 & 2013 & Supriyono & $\begin{array}{c}\text { Pengaruh Risk } \\
\text { Based Capital } \\
\text { thd } \\
\text { Profitabilitas } \\
\text { Pada } \\
\text { Perusahaan } \\
\text { Asuransi } \\
\text { Syariah (Studi } \\
\text { Pada PT. } \\
\text { Asuransi } \\
\text { Takaful dan } \\
\text { PT. Asuransi } \\
\text { Takaful } \\
\text { Keluarga. }\end{array}$ & $\begin{array}{c}\text { Independen : } \\
\text { RBC } \\
\text { Dependen } \\
\text { ROA dan } \\
\text { ROE }\end{array}$ & $\begin{array}{l}\text { Risk Based Capital } \\
\text { pemgaruhnya } \\
\text { signifikan thd } \\
\text { Return On Asset } \\
\text { (ROA) dan } \\
\text { Return On Equity } \\
\text { (ROE) }\end{array}$ \\
\hline
\end{tabular}




\begin{tabular}{|c|c|c|c|c|c|}
\hline 3 & 2014 & Fitriani, & $\begin{array}{l}\text { Pengaruh Risk } \\
\text { Based Capital } \\
\text { terhadap } \\
\text { Profitabilitas } \\
\text { Asuransi } \\
\text { Syari'ah AXA } \\
\text { Mandiri }\end{array}$ & $\begin{array}{c}\text { Independen : } \\
\text { RBC } \\
\text { Dependen : } \\
\text { ROA }\end{array}$ & $\begin{array}{c}\text { Risk Based Capital } \\
\text { tidak } \\
\text { mempengaruhi } \\
\text { denagan } \\
\text { signifikan thd } \\
\text { profitabilitas }\end{array}$ \\
\hline 4 & 2017 & $\begin{array}{c}\text { Nurul } \\
\text { Mubarok, }\end{array}$ & $\begin{array}{c}\text { Pengaruh Risk } \\
\text { Based Capital } \\
\text { thd. } \\
\text { Profitabilitas } \\
\text { usaha asuransi } \\
\text { syari'ah studi } \\
\text { Pada usaha } \\
\text { Asuransi } \\
\text { Terdaftar di } \\
\text { AASI }\end{array}$ & $\begin{array}{c}\text { Independen : } \\
\text { RBC } \\
\text { Dependen : } \\
\text { Profitabilitas }\end{array}$ & $\begin{array}{c}\text { RBC tidak } \\
\text { mempengaruhi } \\
\text { ROA dengan } \\
\text { signifikan dan } \\
\text { ROE } \\
\text { dipengaruhi RBC } \\
\text { secara parsial tapi } \\
\text { tidak signifikan }\end{array}$ \\
\hline 5 & 2018 & Ikaprilia, & $\begin{array}{l}\text { Pengaruh } \\
\text { Pendapatan } \\
\text { premi, } \\
\text { Undermuriting } \\
\text { dan } \\
\text { Solvabilitas } \\
\text { thd } \\
\text { Profitabilitas } \\
\text { Usaha } \\
\text { Asuransi } \\
\text { Syari'ah } \\
\text { terdaftar di } \\
\text { BEI 2013- } \\
\text { 2016 }\end{array}$ & $\begin{array}{l}\text { Independen : } \\
\text { Pendapatan } \\
\text { Premi, } \\
\text { Underwriting, } \\
\text { Solvabilitas } \\
\\
\\
\text { Dependen : } \\
\text { Profitabilitas }\end{array}$ & $\begin{array}{c}\text { ROA } \\
\text { dipengaruhi } \\
\text { signifikan oleh } \\
\text { RBC dan positif } \\
\text { pengaruhnya }\end{array}$ \\
\hline
\end{tabular}

Sumber: Aditya Fadlin Rachman Pratama(2013), Agung Eko Supriyono (2013), Suci Fitriani (2014), Nurul Mubarok Dede Rahayu(2017), Arnisa Ikaprilia (2018).

Sehubungan dengan variabel dependennya ialah ROA (Return On Asset) dan variabel independen RBC (Risk Based Capital). Berdasarkan penelitian sebelumnya diatas, maka didapat hipotesis berupa: RBC berpengaruh signifikan dan positif terhadap ROA Perusahaan Asuransi Kerugian terdaftar di BEI Periode 2013-2018.

\section{Metode Penelitian}

Pada penelitian ini digunakan metode penjelasan (explanatory) dengan pendekatan kuantitatif. Metode explanatory ini adalah penelitian dengan memberi penjelasan hubungan berupa hubungan variabel independen dan dependen yang dikaitkan dengan sebab akibat . Penelitian ini juga meneliti tentang hubungan 2 variabel atau lebih yang selanjutnya akan 
dijelaskan pengaruh serta perubahan yang terjadi pada variabel bersangkutan.

Sedangkan pendekatan kuantitatif dilakukan karena data yang diperoleh berupa data yang berisi seperti rasio solvabilitas (RBC) dan profitabilitas (ROA). Metode ini berfokus terhadap polulasi yang dirangkai menjadi sample yang terpilih secara acak (Sugiyono, 2013).

Alat yang digunakan penulis untuk penelitian ini adalah aplikasi atau software yang dinamakan SPSS dengan versi 23, dan ada 5 teknik analisis dipergunakan di penelitian ini yaitu, Statistik Deskriptif, Asumsi Klasik, Analisis Regresi Sederhana, Analisis Koefisien Determinasi, dan Uji T.

\section{Hasil dan Pembahasan}

\subsection{Hasil}

\subsubsection{Statistik Deskriptif}

Tabel 4.1 Descriptive Statistic

\begin{tabular}{|l|r|r|r|r|r|}
\hline & \multicolumn{1}{|c|}{ N } & \multicolumn{1}{|c|}{ Min } & \multicolumn{1}{|c|}{ Max } & \multicolumn{1}{|c|}{ Mean } & \multicolumn{1}{|c|}{ Std Dev } \\
\hline RBC & 30 & 153,61 & 557,00 & 303,1603 & 106,66612 \\
ROA & 30 &, 66 & 9,43 & 4,6813 & 2,14406 \\
ValidN (listwse) & 30 & & & & \\
\hline
\end{tabular}

Sumber: Output SPSS

Dengan melihat tabel 4.1 diatas, dapat dijelaskan:

Nilai terendah RBC 153,61 diraih oleh PT Asuransi Kresna Mitra (ASMI), yang salah satu penyebabnya dapat dikarenakan aset yang diperkenankan rendah pada tahun 2013. Sedangkan nilai tertingginya adalah 557,00 diraih oleh PT Asuransi Multi Artha Guna Tbk (AMAG) 2015 ini dapat terjadi karena aset yang diperkenankan lebih tinggi dibanding perusahaan lain yang diteliti pada periode yang sama. Standar deviasi sebesar 106,66612 dan rata-rata nya sebesar 303,1603. Dengan adanya aturan 53/PMK.010/2012 yang menetapkan RBC minimal adalah 120\% maka perusahaan yang diteliti dapat dikategorikan sehat.

Nilai terendah rasio ROA adalah 0,66 yang diperoleh PT Asuransi Kresna Mitra Tbk (ASMI) pada 2018 menurun dari tahun sebelumnya, hal dapat terjadi karena adanya peningkatan jumlah aset atau jumlah aset yang menetap namun laba bersihnya turun ditahun terkait. Sedangkan nilai tertingginya adalah 9,43 diraih oleh PT Asuransi Bina Arta Tbk (ABDA) pada 2015 yang dapat terjadi karenakan laba bersih perusahan ini cukup baik dibandingkan perusahaan lain yang diteliti pada periode yang sama. Standar deviasi sebesar 2,144406. Dilihat dari rata-rata yang mencapai 4,6813 dimana rata-rata tersebut telah melewati standar angka ROA menurut Lestari;Sugiharto, 2007 yaitu lebih dari 2\%, maka ROA perusahaan yang diteliti dapat dikategorikan baik dalam mengelola tingkat pengembalian asetnya. 


\subsubsection{Uji Asumsi Klasik}

\section{Uji Normalitas}

Tabel 4.2 Sample Ksmirnov Test

\begin{tabular}{|ll|r|}
\hline & & Unst Residual \\
\hline N. & & 30 \\
Normal Parameters $^{\mathrm{a}}$ & Mean &, 0000000 \\
& Std $_{\circ}$ & 1,59083142 \\
& Deviation. &, 147 \\
Most Extreme & Absolute &, 147 \\
Differences & Positive &,- 147 \\
& Negative &, 147 \\
Test Statistic & &, 096 \\
Asymp. Sig & & (2-tailed) \\
\hline
\end{tabular}

a. Test distribution Normal

b. Calculated from data

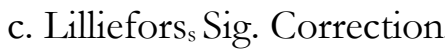

Sumber:Output SPSS

Tabel 4.2 memperlihatkan signifikansi penelitian ini dengan 0,96 yang jika dibandingkan $5 \%(>0,05)$ itu lebih besar berdasarkan teori pada bab sebelumnya diketahui jika signifikansi diatas 0,05 maka data telah dapat dikatakan tersebar normal.

\section{Uji Heterokedastisitas}

Tabel 4.3 Coefficients $^{\circ}$

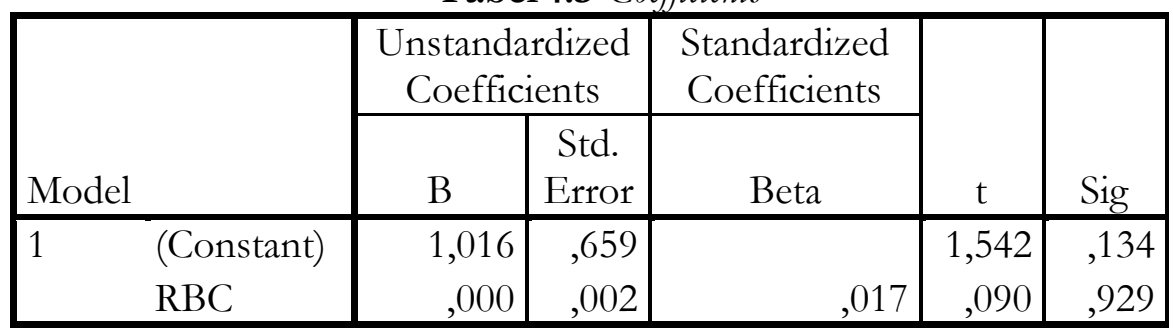

a. Dependent Variable: ABS_RES

\section{Sumber:Output SPSS}

Dari hasil output uji heterokedastisitas dengan metode glejser diatas menunjukkan signifikansi variabel RBC sebanyak 0,929 dan 0,929 > 0,05. Membuktikan pada data yang diteliti tidak terjadi heterokedastisitas. 


\section{Uji Auto Korelasi}

Tabel 4.4 Run Test

\begin{tabular}{|l|r|}
\hline & \multicolumn{1}{|c|}{ Unst Residual } \\
\hline Test Val $^{\mathrm{a}}$ &,- 26551 \\
Cases $<$ TestVal. & 15 \\
Cases $>=$ TestVal. & 15 \\
& 30 \\
Total Cases & 14 \\
Number of Runs &,- 557 \\
Z &, 577 \\
Asymp. Sig. &, 2 tailed) \\
\hline
\end{tabular}

a. Median

Sumber:Output SPSS

Tabel 4.4 memperlihatkan pada penelitian ini signifikansinya adalah 0,577 yang berarti $>$ dari $0,05(>0,05)$. Maka dapat dibuktikan tidak terjadi gejala autokorelasi.

\section{Ringkasan Uji Asumsi Klasik}

Tabel 4.5 Ringkasan Uji Asumsi Klasik

\begin{tabular}{|c|c|c|}
\hline & Sig & Hasil \\
\hline Uji Normalitas & 0,96 & Data Normal \\
\hline $\begin{array}{c}\text { Uji } \\
\text { Heterokedastisitas }\end{array}$ & 0,929 & $\begin{array}{c}\text { Tidak Terjadi } \\
\text { Heterokedastisitas }\end{array}$ \\
\hline Uji Auto Korelasi & 0,577 & Tidak Terjadi Autokorelasi \\
\hline
\end{tabular}

Dari hasil diatas, penelitian dilanjutkan dengan Analisis Regresi Linear Sederhana.

\subsubsection{Analisis Regresi Linear Sederhana}

Tabel 4.6 Coefficients ${ }^{a}$

\begin{tabular}{|c|c|c|c|c|c|}
\hline \multirow[b]{2}{*}{ Model } & \multicolumn{2}{|c|}{$\begin{array}{c}\text { Unstandardized } \\
\text { Coefficients }\end{array}$} & \multirow{2}{*}{$\begin{array}{c}\begin{array}{c}\text { Standardized } \\
\text { Coefficients }\end{array} \\
\text { Beta }\end{array}$} & \multirow[b]{2}{*}{$\mathrm{t}$} & \multirow[b]{2}{*}{ Sig } \\
\hline & B & Std Error & & & \\
\hline $\begin{array}{l}1 \quad \text { (Constanta } \\
\end{array}$ & 596, & 904 & & 659, & ,515 \\
\hline $\mathrm{RBC}$ & 013, & ,003 & 670 & 4,781 & ,000 \\
\hline
\end{tabular}

a. Dependent Var:ROA

\section{Sumber:Output SPSS}

Variabel yang digunakan dalam penelitian ini yaitu solvabilitas perusahaan asuransi dengan metode Risk Based Capital (X) dan Profitabilitas dengan metode Return On Asset (Y). 
Maka persamaan regresinya adalah:

$$
\mathrm{ROA}=0,596+0,013 \mathrm{RBC}
$$

Jelasnya, setiap Risk Based Capital mengalami naik atau turun nilainya 1 kali maka Return On Asset akan naik atau turun juga sebesar 0,596.

\subsubsection{Analisis Koefisien Determinasi}

Tabel 4.7 Model Summary ${ }^{\mathrm{d}}$

\begin{tabular}{|l|r|r|r|r|}
\hline Model & \multicolumn{1}{|c|}{$\mathrm{R}$} & R Square & Adjusted $\mathrm{R}^{2}$ & $\begin{array}{r}\text { Std Errors of } \\
\text { the Estimates }\end{array}$ \\
\hline 1 &, $670^{\mathrm{a}}$ &, 449 &, 430 & 1,61899 \\
\hline
\end{tabular}

a. Predictor (Constant), RBC

b. Dependent Var: ROA

\section{Sumber:Output SPSS}

Pada kolom $\mathrm{R}$ Square di tabel 4.7, terlihat $\mathrm{R}^{2}$ sebesar 0,449 atau 44,9\%. Ini membuktikan variabel Risk Based Capital (RBC) mampu menjelaskan Return On Asset (ROA) sebesar 44,9\% pada perusahaan asuransi terdaftar di BEI. Sedangkan, 55,1\% sisanya dikarenakan faktor yang tidak diteliti di penelitian ini.

\subsubsection{Uji Hipotesis (Uji T)}

Tabel 4.8 Coefficients $^{a}$

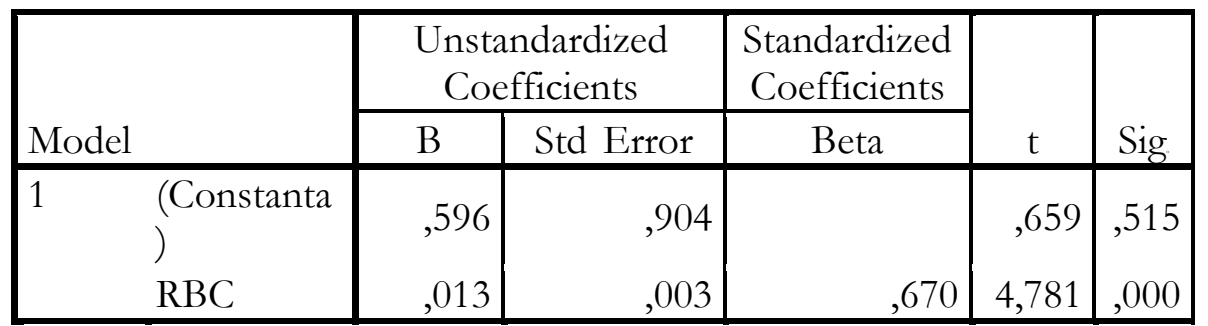

a. Dependent Variable: ROA

\section{Sumber:Output SPSS}

Hasil diatas memperlihatkan $\mathrm{t}$ hitungnya adalah sebesar 4,781sedangkan t tabelnya sebesar 2,045. Dengan T hitung $>\mathrm{T}$ table, menyebabkan Ho ditolak dan variabel Return On Asset (ROA) di pengaruhi secara parsial oleh Risk Based Capital (RBC) pada Perusahaan Asuransi Kerugian yang terdaftar di BEI 2013-2018.

\subsection{Pembahasan}

\subsubsection{Perkembangan Risk Based Capital}

RBC tertinggi untuk periode 2013 - 2018 ada pada PT Asuransi Multi Artha Guna Tbk(AMAG) 2015 yaitu sebesar $557 \%$, untuk perusahaan yang setiap tahunnya memiliki Risk Based Capital yang meningkat ada pada PT Asuransi Kresna Mitra Tbk. Menunjukkan bahwa PT Asuransi Multi Artha Guna Tbk (AMAG) memiliki rasio kesehatan yang paling baik dibandingkan perusahaan asuransi lainnya pada tahun yang sama dan PT Asuransi Kresna Mitra Tbk menjadi perusahaan yang baik dalam hal meningkatkan RBC karena RBC perusahaan tersebut tidak menurun bahkan sejak 2013 - 2018.

Perkembangan RBC pada Perusahaan Asuransi terdaftar di BEI periode 2013 - 2018 
mengalami fluktuasi tiap tahunnya, dimana hanya 1 (satu) perusahaan yang memiliki Risk Based Capital yang terus meningkat setiap tahunnya yaitu PT Asuransi Multi Artha Guna.

Secara keseluruhan perkembangan Risk Based Capital pada Perusahaan Asuransi terdaftar di BEI periode 2013 - 2018 mengalami fluktuatif tetapi dapat dikategorikan sehat karena sudah memenuhi kepmen keuangan No 424/KMK.06/2003 tentang RBC, dimana usaha asuransi wajib memiliki RBC minimal 120\%.

Diantara 5 (lima) perusahaan diatas diketahui pula bahwa pada tahun 2014 RBC cenderung mengalami penurunan yang dapat terjadi karena adanya peningkatan jumlah kewajiban (liabilities) yang salah satu akibatnya adalah telatnya pelaporan klaim asuransi atau berkurangnya keahlian perusahaan dalam memenuhi kewajiban yang bisa datang dari peminimalisir risiko, dimana modal tidak dapat menutupi risiko yang terjadi sehingga saat risiko yang dihadapi malah semakin besar dan tidak dapat ditutupi dengan modal, akhirnya menyebabkan batas tingkat solvabilitas minimum lebih besar dibandingkan tingkat solvabilitasnya yang berikut disertai penurunan tingkat RBC.

Perkembangan RBC yang fluktuatif ini dapat terjadi karena kenaikan maupun penurunan yang terjadi pada komponen - komponen perhitungan RBC seperti, aset yang diperkenankan, liabilitas dan batas minimum tingkat solvabilitas yang mempengaruhi naik dan turunnya RBC pada perusahaan asuransi.

\subsubsection{Perkembangan Return On Asset}

Return On Asset tertinggi untuk periode 2013 - 2018 didapat PT.Asuransi Bina Dana Arta Tbk(ABDA) 2015 yaitu sebesar 9,43\%, dan membuktikan Asuransi Bina Dana Arta Tbk (ABDA) memiliki kemampuan untuk memanajemen aset semaksimal mungkin untuk memperoleh laba perusahaan dibandingkan dengan perusahaan lain yang diteliti pada tahun 2015. Pada tahun 2018 ROA cenderung mengalami penurunan yang dapat terjadi karena adanya peningkatan jumlah aset ataupun jumlah aset yang menetap namun laba bersihnya turun.

Secara keseluruhan perkembangan Return On Asset pada sektor Asuransi terdaftar pada BEI periode 2013-2018 ini fluktuatif tetapi dapat dikategorikan sehat karena sudah memenuhi standar minimum ROA sebesar 2\% (Lestari ;Sugiharto, 2007) meski pada 2015 PT Asuransi Kresna Mitra Tbk menjadi satu - satunya perusahaan memiliki ROA terendah yaitu $1,64 \%$.

Perkembangan Return On Asset pada sektor asuransi terdaftar pada BEI 2013 - 2018 mengalami fluktuasi tiap tahunnya. Fluktuasi ini dapat terjadi dikarenakan kenaikan maupun penurunan aset dan laba bersih yang akan mempengaruhi kenaikan serta penurunan ROA perusahaan asuransi.

\subsubsection{Pengaruh Risk Based Capital terhadap Return On Asset}

Berdasarkan uji hipotesis diatas diperoleh hasil yaitu sebesar 4,781 didapat sig $<0,05$, lalu perbandingan Thitung dan Ttabel diperoleh hasil Thitung $>$ Ttabel yaitu 4,781 $>2,045$ yang berarti $\mathrm{H}_{1}$ diterima maka Risk Based Capital terhadap Return On Asset berpengaruh secara signifikan serta dengan nilai koefisien regresi Risk Based Capital yang sebesar 0,13 dengan nilai positif, maka bahwa Risk. Based Capital berpengaruh positif dan signifikan terhadap Return On Asset perusahaan asuransi.

Jika ada peningkatan nilai Risk Based Capital maka akan meningkatkan nilai Return On Asset. Sedangkan berdasarkan uji koefisien determinasi diatas, R Square menunjukkan angka 0,449 yang berarti perubahan Risk Based Capital akan berpengaruh terhadap perubahan Returm 
On Asset sebesar 44,9\% dimana 55,1\% sisanya disebabkan oleh variabel lain yang tidak diteliti dalam penelitian ini.

Hasil ini sejalan dengan dua penelitian sebelumnya yang dilakukan oleh (Pratama, 2013), yang meneliti mengenai "Pengaruh Risk Based Capital, Penerimaan Premi, dan Beban Klaim terhadap Profitabilitas (ROA) pada Perusahaan Asuransi Kerugian" mendapat hasil berupa RBC berpengaruh parsial terhadap ROA dan penelitian (Ikaprilia, 2018) yang meneliti mengenai "Pengaruh Pendapatan premi, Underwriting dan Solvabilitas terhadap Profitabilitas pada Perusahaan Asuransi Syariah terdaftar di BEI 2013-2016" mendapatkan hasil berupa RBC berpengaruh positif terhadap ROA

\section{Penutup}

Berdasarkan Uji Hipotesis, tepatnya pada Uji T, dengan signifikan dibawah 5\% dan koefisien regresi bersifat positif(+) maka Risk Based Capital berpengaruh signifikan dan positif terhadap Return On Asset. Dimana setiap perubahan Risk Based Capital dapat mempengaruhi perubahan Return On Asset sebesar 44,9\% dan sisanya disebabkan oleh variabel lain yang tidak diteliti dalam penelitian ini.

Serta saran untuk mengingatkan bagi internal perusahaan asuransi yaitu untuk selalu menjaga Risk Based Capital selalu diatas 120\%, yang diseimbangkan pula dengan menjaga Return On Asset dengan memilih investasi yang baik agar aset yang dikelola dapat menambah laba perusahaan sehingga perusahaan terkait dapat dikategorikan sehat dan menguntungkan.

Saran lain yaitu untuk peneliti selanjutnya diharapkan menambahkan variabel yang belum ada dalam penelitian ini. Misalkan variabel dependen selain ROA dapat dengan menambahkan variabel solvabilitas lain yaitu Return On Equity maupun menambah variabel Investasi serta dapat menambah variabel independen selain $R B C$, seperti Penerimaan Premi dan Beban Klaim agar dapat diperoleh hasil yang lebih akurat. Selain itu menambah periode penelitian dan sampel penelitian juga akan mengacu pada penelitian yang lebih akurat.

\section{Daftar Pustaka}

Agustin, F., Suangga, A., \& Sugiharto, B. (2018). Pengaruh Premium Growth Ratio, Risk Based Capital Dan Hasil Investasi Terhadap Profitabilitas Perusahaan Asuransi Umum Yang Terdaftar Di Bursa Efek Indonesia Tahun 2010-2014. ACCRUALS (Accounting Research Journal of Sutaatmadja), 53-65.

Budiarjo, R. S. (2015). Pengaruh Tingkat Kesehatan Keuangan Perusahaan Asuransi Terhadap Peningkatan Pendapatan Premi. Fakultas Ekonomi Universitas Yogyakarta.

Fitriani, S. (2014). Pengaruh Risk Based Capital terhadap Profitabilitas Asuransi Syariah AXA Mandiri. UNISBA.

Ganie, J. (2013). Hukum Asuransi Indonesia. Sinar Grafika.

Hanafi, A. ; M. (2016). Analisis Laporan Kenangan (4th ed.). UPP STIM YKPN.

bttps:// wmw.idx.co.id/. (n.d.). https://www.idx.co.id/

Ikaprilia, A. (2018). Pengaruh Pendapatan premi, Underwriting dan Solvabilitas terhadap

Profitabilitas pada Perusahaan Asuransi Syariah terdaftar di BEI 2013-2016. LAI Surakarta.

INDONESIA, I. A. (2007). PSAK. Salemba Empat.

Kasmir. (2014). Bank dan Lembaga Kenangan Lainnya. Rajawali Pers.

No 424/KMK.06/2003. 
No 481/KMK.017/1999.

Lestari ;Sugiharto, T. (2007). Kinerja Bank Devisa dan Bank Non Devisa dan Faktor-faktor yang Mempengaruhinya. PESAT, 2.

Ludovicus, S. (2006). Memahami Akuntansi Asuransi Kerugian (Accounting For General Insurance). PT Prima Mitra Edukarya.

Magee, J. (1955). General Insurance. RD Irwin.

Mubarok, N. (2017). Pengaruhrisk Based Capital thd. Profitabilitas perusahaan asuransi syariah studi Pada perusahaan Asuransi Yang Terdaftar di AASI. UIN Palembang.

Pratama, A. F. R. (2013). Pengaruh Risk Based Capital, Penerimaan Premi, Beban Klaim terhadap Profitabilitas Perusahaan Asuransi Kerugian. FISIP UI.

Salim, A. (1995). Dasar-dasar Asuransi. Raja Grafindo Persada.

Sastri, I. A. I. P., Sujana, E., \& Sinarwati, N. K. (2017). Pengaruh Pendapatan Premi, Hasil Underwriting, Hasil Investasi Dan Risk Based Capital Terhadap Laba Perusahaan Asuransi (Studi Empiris pada Perusahan Asuransi yang Terdaftar di Bursa Efek Indonesia periode 2011-2015). E-Journal S1 Ak Universitas Pendidikan Ganesha, 7(1), 1-11.

Sucipto. (2003). Penilaian Kinerja Keuangan. AkuntansiUniversitas Sumatera Utara.

Sugiyono. (2013). Metode Penelitian Pendidikan Pendekatan Kuantitatif, Kualitatif, dan R $\odot D$. Alfabeta.

Supriyono, A. E. (2013). Pengaruh Risk Based capital terhadap Profitabilitas pada Perusahaan Asuransi Syariah: Studi Kasus pada PT. Asuransi Takaful Umum dan PT. Asuransi Takaful Keluarga Periode 2004-2010. In Jurnal Aktiva: Riset Akuntansi dan Kenangan (Vol. 1, Issue 1). agungekosupriyono@gmail.com

UU No. 21992 Tentang Usaha Perasuransian.

Winarni, S. G.; F. (2005). Manajemen Kenangan. Media Pressindo. 